\title{
AGRICULTURA FAMILIAR E AGRONEGÓCIO: EXPRESSÕES DO ESPAÇO RURAL BRASILEIRO NO LIVRO DIDÁTICO DE GEOGRAFIA DO ENSINO FUNDAMENTAL II
}

Lidiane Aparecida Alves ${ }^{1}$

Resumo: O objetivo do artigo é refletir sobre a agricultura familiar e o agronegócio no atual contexto do rural brasileiro e como estes temas são abordados no âmbito do ensino fundamental II. Para atingir o objetivo, realizou-se uma reflexão sobre a temática considerando as discussões teóricas e avanços em termos acadêmicos e político institucional. Em seguida, analisou-se a abordagem da temática nos livros didáticos escolhidos. De modo que, constatou-se diferenças epistemológicas e no discurso sobre o agronegócio e a agricultura familiar, sendo que apesar das obras abordarem os problemas inerentes as duas formas de produção presentes no campo brasileiro, no livro $\mathrm{B}$, o tema é tratado de modo mais abrangente e crítico.

Palavras-chave: Agricultura familiar. Agronegócio. Ensino de Geografia. Livro didático.

\section{FAMILY AGRICULTURE AND AGRIBUSINESS: EXPRESSIONS OF THE BRAZILIAN RURAL SPACE IN THE GEOGRAPHY TEXTBOOK OF ELEMENTARY EDUCATION II}

Abstract: The purpose of this article is to reflect about family agriculture and agribusiness in the brazilian rural current context and how these themes are addressed in the scope of elementary education II. In order to reach the objective, a reflection on the subject was made considering the theoretical discussions and advances in academic and institutional political scope. Next, the approach of the theme in the chosen textbooks was analyzed. Thus, epistemological differences and the discourse on agribusiness and family agriculture were observed, and although the work addresses the inherent problems of the two forms of production present in the Brazilian field, in book $\mathrm{B}$, the theme is treated in a more comprehensive and critical.

Keywords: Family agriculture. Agribusiness. Geography teaching. Textbook.

\section{AGRICULTURA FAMILIAR Y AGRONEGOCIO: EXPRESIONES DEL ESPACIO RURAL BRASILEÑO EN EL LIBRO DIDÁCTICO DE GEOGRAFÍA DE LA ENSEÑANZA FUNDAMENTAL II}

Resumen: El propósito del artículo es reflexionar sobre la agricultura familiar y el agronegocio en el actual contexto rural brasileño y cómo estos temas se abordan en el ámbito de la enseñanza fundamental II. Para alcanzar el objetivo, se realizó una reflexión sobre la temática considerando las discusiones teóricas y avances en ámbito académico y político institucional. A continuación, se analizó el abordaje de la temática en los libros didácticos escogidos. De modo que, se constataron diferencias epistemológicas y en el discurso sobre el agronegocio y la agricultura familiar, siendo que a pesar de las obras abordar los problemas inherentes a las dos formas

1 Prefeitura Municipal de Educação, Secretaria de Educação, Uberlândia, Brasil, lidianeaa@yahoo.com.br, https://orcid.org/0000-0002-0641-6993 
de producción presentes en el campo brasileño, en el libro $\mathrm{B}$, el tema es tratado de modo más amplio y crítico.

Palabras clave: Agricultura familiar. Agronegócio. Enseñanza de Geografía. Libro didáctico.

\section{Introdução}

A coexistência da agricultura familiar e do agronegócio no espaço rural brasileiro vincula-se diretamente à formação sócio-espacial do próprio país, de modo que os embates e dilemas entre estas duas formas de organização da produção no campo devem ser analisados e entendidos enquanto uma realidade construída e modificada historicamente que conjuga fatores sociais, econômicos, políticos, técnicos e culturais, acumulados em no seu processo de (re)elaboração. A retomada à períodos anteriores do processo da formação espacial brasileira é, portanto, essencial para a compreensão das relações de produção, bem como das características predominantes e dos fatores que condicionam a conjuntura contemporânea.

Historicamente, desde o período colonial, o Brasil já assumiria um papel de produtor de commodities. Sendo que após cinco séculos, muitos dos resquícios do Brasil Colônia ainda permanecem a incomodar ou, paradoxalmente, a justificar uma realidade que ignora camponeses, indígenas, quilombolas e trabalhadores urbanos; desde o ciclo da cana-de-açúcar até o atual momento vivenciado pelo campo brasileiro, a lógica produtiva sempre esteve pautada na produção para atender ao mercado externo, perpetuando assim a chamada por Gonçalves (2005) "colonialidade" do poder, a partir de dispositivos disciplinares que buscam assegurar o fluxo de matérias-primas da periferia em direção ao centro do sistema-mundo moderno-colonial.

Segundo esse modelo agroexportador, a grande propriedade sempre se impôs como modelo socialmente reconhecido, especialmente nas políticas agrícolas, enquanto a agricultura familiar sempre ocupou lugar secundário e subalterno, sendo a história do camponês no Brasil marcada pelas lutas para conseguir um espaço próprio na economia e na sociedade. De tal modo, neste texto busca refletir sobre os embates e dilemas entre a agricultura familiar e o agronegócio no contexto brasileiro e a forma de abordagem de tal conteúdo no âmbito do ensino fundamental II.

Para atingir este objetivo, primeiramente, realizou-se levantamentos bibliográficos sobre o tema para empreender uma reflexão sobre questões teóricas 
da agricultura familiar e do agronegócio e suas conformações no espaço rural brasileiro, considerando as discussões e avanços no âmbito acadêmico e político institucional. Em seguida, procurou-se analisar e tecer considerações acerca dos livros didáticos escolhidos, que, de acordo com a ABRELIVROS (Associação Brasileira de Livros) estão entre os mais vendidos e inscritos no PNLD, 2017. As obras selecionadas foram: Expedições Geográficas, dos autores Melhem Adas e Sergio Adas, da editora Moderna e o livro Para Viver Juntos, de Fernando dos Santos Sampaio e Marlon Clovis Medeiros, da Editora Sm. Como a temática inserese nos conteúdos estudados no sétimo ano, os livros referem-se a este ano, do ensino fundamental II.

Além do texto escrito, outras formas de comunicação como as imagens, gráficos, tabelas, mapa, etc. também foram consideradas para a análise, a partir da qual constatou-se diferenças epistemológicas e variação no discurso sobre o agronegócio e a agricultura familiar, enquanto formas de produção presentes no espaço rural brasileiro. Ainda que em ambos os livros sejam apresentados problemas inerentes ao campo brasileiro, considerando as duas formas de produção, destaca-se que no livro $\mathrm{B}$, a abordagem é mais abrangente e crítica.

\section{O agronegócio e a acumulação de capital}

De acordo com os economistas norte-americanos da Universidade de Harvard, John H. Davis e Ray A. Goldberg (1957), que estudaram a evolução e reestruturação da agricultura e criaram o termo Agribusiness (usual durante a década de 1980 sem tradução) ou agronegócio (com utilização difundida a partir de meados dos anos 90), o conceito decorre da complexidade desse setor, que envolve segundo a ABAGRP (2019, s/p) "a soma total das operações de produção e distribuição de suprimentos agrícolas, das operações de produção nas unidades agrícolas, do armazenamento, processamento e distribuição dos produtos agrícolas e itens produzidos a partir deles. E envolve desde a pesquisa científica até a comercialização de alimentos, fibras e energia", conforme ilustrado na figura 1.

Ademais, na visão dos estudiosos o desenvolvimento da nova realidade relaciona-se com o avanço técnico-científico, da disponibilidade de grandes extensões de terra, assim como é reflexo de mudanças estruturais na economia mundial; onde a produção passa a ocorrer de modo sistêmico e de maneira interrelacionada com outros setores. Daí decorre também a noção de commodity 
system approach (Cadeia de Produção Agro-Industrial), que explica a estrutura organizacional do agronegócio.

Figura 1: Principais operações na atividade do agronegócio.

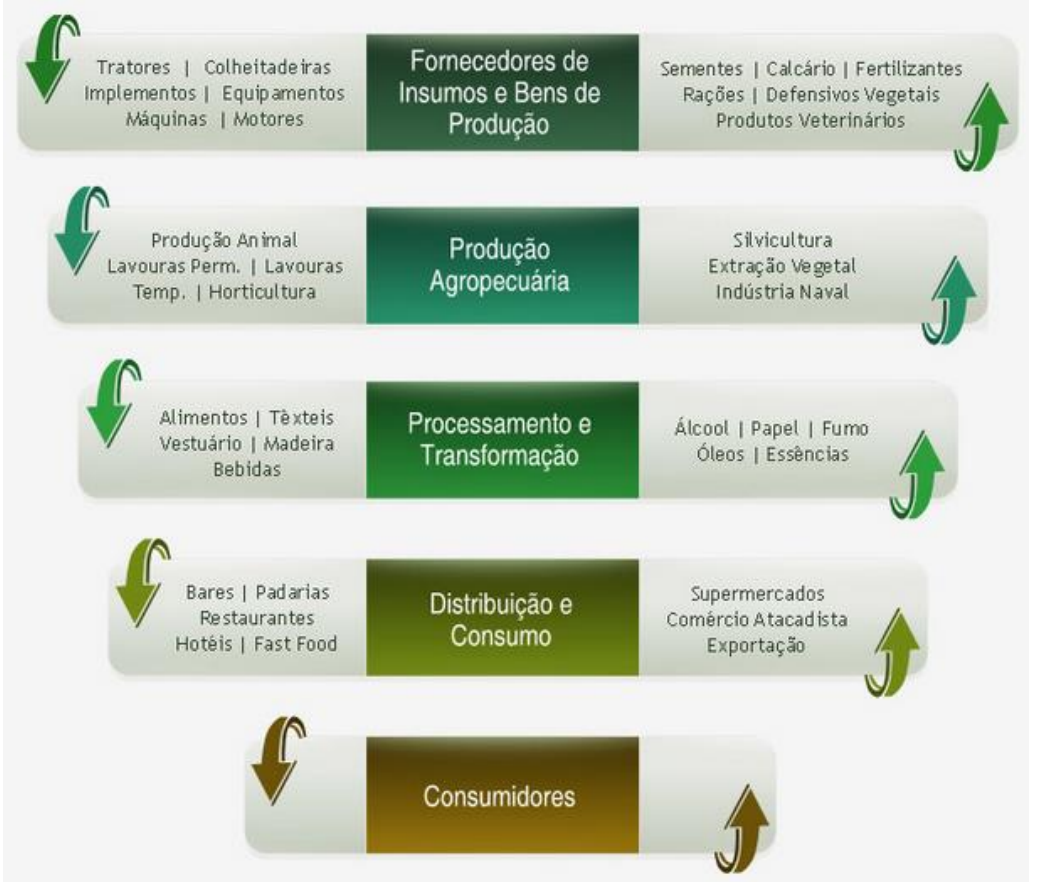

Fonte: Abagrp, 2019. Disponível em: < http://www.abagrp.org.br/agronegocioConceito.php>.

Ao considerar as Analyse de Filières (ou Cadeias de Produção) observa-se que estas encontram segmentadas em três macrossegmentos, de antes da porteira (insumos), ou seja, a parte anterior à produção rural ou montante do agronegócio; a produção rural e, por fim a parte depois da porteira (comercialização), ou seja, setores que recebem a produção dos produtores rurais ou jusante do agronegócio.

A difusão do agronegócio insere-se no âmbito da "Revolução Verde", ocorrida na década de 1970, caracterizado por um novo paradigma produtivo dominante, em se que se utiliza intensamente da ciência e da tecnologia, da especialização produtiva e da politica econômica neoliberal, onde as grandes empresas do agronegócio que comandam os circuitos espaciais produtivos, culminando assim em uma agricultura científica globalizada, conforme a denominação utilizada por Santos (2006) para se referir ao modelo de produção do campo em escala mundial, em que há a materialização do meio técnico-científico-informacional, ou seja, que depende cada vez mais dos auspícios da ciência, da técnica e da informação para obter a produtividade e a rentabilidade e estão calcados em objetivos pragmáticos, tanto mais provavelmente alcançados, quanto mais claro for o cálculo na sua escolha e na sua implantação. Há que se destacar ainda que, neste contexto materializou a modernização "conservadora", a qual "efetivamente resolveu o problema dos níveis 
de produção e produtividade no campo [...], contudo, não só manteve intocada a propriedade fundiária como teve um custo social muito alto" (GRAZIANO DA SILVA, 2014, p.163).

\section{Conforme Delgado}

Por exemplo, na década de 1970, o governo da ditadura militar promoveu um processo de modernização conservadora que concebeu o rural como sinônimo de agrícola e o desenvolvimento rural como idêntico à modernização agrícola, produzindo transformações socioeconômicas no meio rural que trouxeram resultados bastante penosos para os trabalhadores rurais e muito favoráveis às elites agrárias, agrícolas e agroindustriais (DELGADO, 2010, p. 29).

De acordo com Elias (2003), no Brasil a modernização do campo não foi apenas "conservadora", mas também "dolorosa", na medida em que só se tornou possível graças ao amparo financeiro e com a regulação geral do Estado, privilegiando culturas (voltadas ao mercado externo), áreas (grandes propriedades inseridas na região mais dinâmica, o Centro-Sul) e produtores (grandes proprietários de terra), com pesado ônus para a maior parte da sociedade.

No que concerne à sua estrutura de forma objetiva, Graziano (1998) afirma que o agronegócio representa "um agregado de subsistemas inter-relacionados por fluxos de troca".

Já considerando as relações e interesses em fortalecer e ampliar a dinâmica de acumulação capitalista no campo, pode-se destacar as colocações de Delgado (2010b), de Fernandes (2006) e de Porto Gonçalves apud Oliveira (2006) . Para o primeiro autor,

O agronegócio, na acepção brasileira do termo, é uma associação do grande capital agroindustrial com a grande propriedade fundiária. Essa associação realiza uma estratégia econômica de capital financeiro, perseguindo o lucro e a renda da terra, sob patrocínio de políticas de estado. (DELGADO, 2010b, p.113).

Em perspectiva similar Fernandes (2006, p. 1) alerta que,

A palavra agronegócio é nova (década de 1990), e é também uma construção ideológica para tentar mudar a imagem latifundista da agricultura capitalista. O latifúndio carrega em si a imagem de exploração, trabalho escravo, extrema concentração da terra, coronelismo, clientelismo, subserviência, atraso político e econômico. É, portanto, um espaço que pode ser ocupado para o desenvolvimento do país: latifúndio está associado à terra que não produz e pode ser usada para reforma agrária. [...] $\mathrm{A}$ imagem do agronegócio foi construída para renovar a imagem da agricultura capitalista, para "modernizá-la". É uma tentativa de ocultar o caráter 
concentrador, predador, expropriatório e excludente para relevar somente o caráter produtivista. Houve o aperfeiçoamento do processo, mas não a solução dos problemas: o latifúndio efetua a exclusão pela improdutividade, - agronegócio promove a exclusão pela intensa produtividade (FERNANDES, 2010, p. 1).

Já Oliveira (2006) concordando e reafirmando as colocações de Carlos Walter Porto Gonçalves, ressalta que a agri-cultura relaciona-se à atividade econômica milenar de produção dos alimentos necessários e fundamentais à existência da humanidade, enquanto o agro-negócio visa à produção de commodities (mercadorias) para o mercado mundial. Sendo que ao se assentar no sistema de plantation, o agronegócio coloca em risco a biodiversidade e a saúde humana, posto que provoca rápido desmatamento, combinado com o uso em altíssima escala dos mais variados tipos de agrotóxicos, que gera contaminações pelos resíduos em alimentos, no ambiente, desinsetizações e exposição ocupacional ${ }^{2}$, especialmente nos biomas do Cerrado e da Floresta Amazônica ${ }^{3}$; ameaça também a capacidade de produção de alimentos, haja vista a redução da área plantada de arroz, feijão, mandioca e banana, em suas diversas variedades. Acrescenta-se ainda os problemas relacionados aos empregos gerados e suas condições, haja vista que além da redução no número de trabalhadores, em função da mecanização, ocorre maior exigência de mão-de-obra qualificada, além disso não é incomum a terceirização e mesmo trabalhadores em condições análogas à do trabalho escravo; em relação à concentração da terra e a consequente expulsão dos trabalhadores do campo, posto que o agronegócio fomenta o problema de grilagem de terras, sobretudo nas áreas de expansão do cultivo de produtos de exportação, principalmente a soja.

Por fim, conforme alerta vários estudiosos, cabe ressaltar os riscos inerentes à "colonialidade" do poder (e do saber), utilizando o termo cunhado por Aníbal Quijano e difundido por Carlos Walter Porto Gonçalves, que comanda nossa formação social e aparece na ideia de modernização, gerando as violências e um legado de desigualdade e injustiças sociais que têm estruturado as relações sociais e de poder no Brasil ao longo de sua História.

\footnotetext{
2 Segundo Faria (2012) apesar do Brasil ser o maior consumidor mundial de agrotóxicos, falta monitoramento do consumo, da exposição e dos efeitos dos agrotóxicos sobre a saúde no país.

${ }^{3}$ De acordo com Castillo (2007, p.23) essas áreas reuniam as características edafo-climáticas e a topografi a, de um lado, a grande concentração fundiária, a urbanização incipiente e dispersa, a baixa densidade em infra-estruturas, a distância em relação aos portos exportadores, um estoque de terras ainda a ser ocupado pelo agronegócio, de outro lado - tudo isso junto (num contexto de globalização econômica) criou possibilidades inéditas para a atuação de grandes empresas.
} 
Neste sentindo, como aponta Oliveira (1987) como parte da lógica capitalista de recriação do campesinato subordinando-o a expansão capitalista, os camponeses e/ou de agricultores familiares se veem obrigados a se subordinarem à lógica de produção do agronegócio. Segundo Bruno (2016) a relação do patronato rural e agroindustrial com os agricultores familiares faz parte de uma história de exploração e de subordinação e pressupõe a utilização dos mecanismos de dominação simbólica cuja finalidade é apagar ou naturalizar as desigualdades sociais a fim legitimar regras de inclusão e exclusão que fazem parte dessa relação, que se impõe segundo uma competitividade sistêmica conforme uma postura de mercado e uma cultura empresarial. De acordo com a autora as relações se estabelecem a partir de dois modos que se complementam, quais sejam: a instituição de "contratos de integração" celebrados no interior das cadeias produtivas dos complexos agroindustriais (CAls) e a filiação à Organização das Cooperativas Brasileiras (OCB).

Sobre tais formas de subordinação dos agricultores familiares ao agronegócio a autora explica que:

\begin{abstract}
Os "contratos de integração" [...] em sua maioria voltada para a engorda de animais de pequeno porte das cadeias produtivas de grandes indústrias como Sadia e Perdigão. Também se referiam à produção de grãos e a acordos entre plantadores de fumo e a indústria fumageira, dentre outros. Nesses contratos, riscos e prejuízos são sempre de responsabilidade dos agricultores familiares, cabendo às empresas agropecuárias privilégios, garantias e lucro. Juntamente com a implementação dos sistemas de integração há uma intensificação da propaganda, caracterizando esse processo como "parceria do ganha-ganha". Argumentos que ressaltavam as benesses da integração para os pequenos agricultores proprietários argumentando que eles não seriam "escravos" da agroindústria, garantindo que não haveria perdas, só ganhos, e caracterizando a parceria como condição para acesso à tecnologia e, obviamente, omitindo os ganhos para as empresas. [...] Sobre a filiação ao sistema OCB, as desigualdades e as tensões se expressam na própria estrutura organizativa da entidade, visto que a direção e as decisões concentram-se nas mãos das grandes cooperativas, enquanto o agricultor familiar situa-se nas bases da organização. E uma das justificativas das lideranças do cooperativismo empresarial da necessidade de parceria é a alegação do despreparo do Estado na garantia da reprodução social do agricultor familiar vocacionado, pois não dispõe de uma infraestrutura de armazéns para grãos e cereais. $O$ despreparo do Estado "abre espaço ao protecionismo e ao paternalismo" (BRUNO, 2016, p.145-146).
\end{abstract}

Conforme destacam autores como Paulino (2005) e Oliveira (1997), muitas vezes esta subordinação, que são formas encontradas pelos camponeses para se manter na terra, possui facetas invisíveis, como a monopolização do território pelo capital e/ou a territorialização do capital nos espaços onde a monopolização do 
território pelo capital se expande. Neste sentido, no primeiro caso nota-se a inserção dos trabalhadores, não por meio da mercadoria trabalho, mas através da apropriação das mercadorias produzidas pelo trabalho, enquanto no segundo caso, a força de trabalho assume-se como mercadoria.

A lista de consequências negativas do agronegócio é extensa e amplamente conhecida ainda que relegada. A mídia se coloca a serviço do agronegócio e, segundo a lógica do capital centra massivamente seus discursos na perspectiva neoliberal, segundo a qual o Estado é lento e ineficiente, ao contrário da iniciativa privada e do capital que é eficiente, ainda que paradoxalmente, dependa do Estado para uma série intervenções e garantias, como as melhorias na infraestrutura e logística para escoamento de produtos e os programas de financiamentos, tanto para o custeio (financiar a aquisição de insumos, fertilizantes, sementes e produtos necessários para o processo produtivo), quanto para investimentos (ampliar, diversificar e modernizar a produção). Portanto, seus discursos, sem divulgar as consequências nefastas da expansão do agronegócio, disfarçados de um desenvolvimento econômico, enfatizando a eficiência econômica e produtiva deste setor, a mídia apresenta-se a serviço dos grupos empresariais, ainda que não seja novidade, conforme destacam Matos e Pessôa (2012) que em qualquer lugar no qual o agronegócio territorializa-se, o capitalismo no campo produz, exclui e degrada, afinal,

O agronegócio é devastador. Imensas áreas de florestas e do cerrado estão sendo ilegalmente desmatadas, secando nascentes e mananciais, sugados pelo ralo das monoculturas, pastos de capim, carvoarias, mineradoras e madeireiras. Os agrotóxicos, despejados por aviões e tratores, estão contaminando solos, águas, ar e as plantações camponesas, causando doenças e mortes. (CANUTO, 2004, p.10).

Entretanto, é amplamente reconhecido por vários estudiosos como Oliveira (1997), que paradoxalmente ao desenvolvimento do agronegócio, em suas relações essencialmente capitalistas, permanecem e surgem as diversas formas de adaptação, resistência e reinvenção das formas tradicionais de produção, que são responsáveis pela soberania alimentar dos povos, pela preservação dos recursos naturais, dos saberes, dos modos de vida e cultura históricos. 


\section{Agricultura Familiar: Entre a complexidade e a potencialidade}

A agricultura familiar é um termo que vem sendo alvo de embates teóricos, tanto na Geografia quanto na Economia e na Sociologia, após muito tempo ter sido relegado ao esquecimento. Somente no final da década de $1990 \mathrm{com}$ a democratização e várias discussões apontarem a importância das unidades de produção familiar para o desenvolvimento econômico e modernização da nação, que tal forma de organização da produção adquiriu visibilidade. Conforme observa Wilkinson (2003), foi um "investimento político e acadêmico nada desprezível" que conseguiu transformar a "pequena produção" em "agricultura familiar". Ainda que segundo Navarro e Pedroso (2011) a institucionalização da expressão não tenha reconhecido aspectos considerados cruciais, como o fato de não existir na teoria social nenhuma perspectiva analítica que tenha agricultura familiar como um de seus conceitos, ou o de desconsiderar, no caso brasileiro, a natureza econômica da agricultura, pois os critérios legais obedeceram a outras motivações.

De fato, a partir desse momento, os trabalhos referentes à agricultura familiar ganharam um espaço relativamente amplo, os quais segundo Hespanhol (2000), em linhas gerais, podem ser agrupados em duas tendências: como relação não capitalista e como subordinada ao capital. A primeira tendência seria decorrente da fragilidade com que o capital se inseriu na agricultura brasileira, possibilitando a criação e permanência de formas não capitalistas de produção em que o "roçado" possibilitaria o acesso aos bens necessários à reprodução. A segunda tendência, por sua vez, seria fruto da consolidação das inovações tecnológicas que foram absorvidas pelas pequenas unidades de produção, principalmente via integração com agroindústrias.

Assim sendo, a partir da segunda metade da década de 1980 e início dos anos de 1990, muitos autores começaram a questionar a utilização da terminologia pequena produção para se referir às unidades de produção familiares, em decorrência do contexto instalado, visto que,

[...] sob a denominação de pequena produção estavam agrupadas diferentes formas de acesso à terra e de relações de produção de diversas categorias como proprietários, parceiros, arrendatários, ocupantes, etc., que estruturados com base no trabalho dos membros da família, tinham como objetivo principal, a subsistência do grupo doméstico, comercializando o excedente no mercado. Entretanto, com o processo de modernização da agricultura, parcela desses produtores, com capacidade de capitalização, de acesso ao crédito de absorção tecnológica, de inserção ao mercado, etc. passou a se diferenciar dos demais, tornando dif́cil sua identificação 
apenas como produtores de pequenos volumes (em termos de quantidade ou de valores) ou de gêneros de subsistência. (HESPANHOL, 2000, p. 76).

Existem inúmeras controvérsias, definições e caracterizações, pois ao ser composto de várias categorias, com grande variação de renda, nível de capitalização e sistemas de produção, como destaca Carneiro (2008) o segmento familiar da agricultura brasileira é muito heterogêneo. Segundo Wanderley (2000, p.2), o conceito de agricultura familiar como categoria genérica é entendida como "aquela em que a família, ao mesmo tempo em que é proprietária dos meios de produção, assume o trabalho no estabelecimento produtivo", sendo que grosso modo, tem como base de sustento o que a família produz, vendendo ou não o excedente.

Hespanhol (2000) e Mendes (2005), entre outros autores, destacam que grande parte das análises referentes à agricultura familiar, desenvolvidas a partir desse momento, tem em comum a concepção de unidade familiar como aquela estruturada no tripé trabalho, terra e família, ou seja, conforme a proposta da FAO/INCRA e o pensamento de Lamarche (1993), que consideram a agricultura familiar como a unidade de produção onde propriedade e trabalho estão intimamente ligados à família.

Conforme Sérgio Schneider, em seu livro "A Diversidade da Agricultura Familiar" (2009), não há consenso entre os autores que estudam a estrutura agrária brasileira quanto aos modos de inserção ou integração das formas familiares de trabalho ao capitalismo e, assim, há duas formas de interpretação. Enquanto a primeira encara a transformação do campesinato para agricultura familiar como uma associação indistinta entre agricultura familiar e capitalismo (ou agronegócio); a outra reduz toda forma de produção familiar à condição camponesa. De fato há pequenas propriedades mais modernas e outras mais arcaicas.

$\mathrm{Na}$ mesma perspectiva Paulino (2006), muitos camponeses não se reconhecem como tal sendo este um termo recente, sendo que para a autora a partir do progresso técnico, os camponeses, índios, imigrantes ex. escravos, se tornaram agricultores familiares ou proletários. A autora destaca que no contexto atual o campesinato passou por transformações. Contudo, continua com papel fundamental no provimento de alimentos fundamentados na lógica de que a terra é sinônimo de vida, meio de trabalho, valor de uso, sendo sua lógica a satisfação das necessidades de consumo 
Já para Fernandes (2001), toda agricultura camponesa é familiar, todavia, nem todo agricultor familiar é camponês, sendo necessário, portanto, entender cada um desses sujeitos. Neste sentido, o primeiro decorre de uma forma de relação social de produção histórica com valores distintos daqueles intrínsecos ao capitalismo, como a luta de classe e a preservação dos saberes e culturas tradicionais. Por outro lado, o agricultor familiar, tem passado não campesinato, mas adaptou-se às condições modernas de produzir e de viver em sociedade, neste caso pode haver as empresas familiares que podem ser grandes ou pequenas, sendo a característica fundamental que os proprietários sejam membros da família.

Deste modo, considerando as transformações na produção rural, não há entre os estudiosos um consenso sobre o destino e significado deles, apesar de ser amplamente reconhecida a importância destes diferentes atores sociais do campo. Afinal, independe se refere-se ao camponês ou ao agricultor familiar, o fato é que estes têm importante papel social para o desenvolvimento do país, pois a agricultura que praticam, a chamada agricultura camponesa ou familiar, consiste em um fator mitigador do êxodo rural e gerador de recursos para as famílias com menor renda, contribui para a geração de riqueza, considerando a economia não só do setor agropecuário, mas do próprio país. Sendo que além deste caráter mais distributivo do ponto de vista social, posto que é reconhecido que nos locais com maior concentração de agricultores familiares, a desigualdade é menor e, por conseguinte os índices de desenvolvimento estão entre os maiores, esta agricultura apresenta práticas ambientais mais sustentáveis.

Tradicionalmente a agricultura familiar tem sido responsável pela produção de alimentos destinados à subsistência e ao consumo de parte da população urbana, porém, historicamente as políticas agrícolas e conforme destacado por Sampaio (2002), o sistema econômico pouco valoriza este setor e os seus produtos, por conseguinte seus níveis de renda são baixos.

Os camponeses enfrentam alguns problemas de difícil solução, tais como, a escassez da terra; a reduzida e não-qualificada mão-de-obra; o gerenciamento espontâneo e superficial; a insuficiência ou mesmo a falta do associativismo; a precária comercialização; a escala de produção baixa; a não-agregação de valor à produção; a incompatibilidade das tecnologias; a reduzida formação e informação; a inexistência de política agrícola; o desfavorecimento presente nas relações de troca, dentre outros. Deste modo, como estratégia para a reprodução dos agricultores, 
consolida-se no meio rural por alienação ou vontade própria do agricultor, a combinação de várias atividades.

As noções da agricultura em tempo parcial (Part-time farmer) e pluriatividade (pluriactivitè) emergiram na década de 1930 na Europa, para designar os processos de diversificação de culturas e de atividades dos agricultores a fim assegurar a complementação da renda, maior estabilidade, menor dependência do mercado, entre outras. Essas noções passaram por um período de esquecimento e após a década de 1970 foram introduzidas no Brasil e amplamente, sobretudo a partir dos anos de 1990 por estudiosos como Anjos (1995); Alentejano (1999); Schneider (1999); Carneiro (2008) entre outros.

Alentejano (1999) destaca que embora essas expressões designem o mesmo fenômeno, muitas vezes sejam utilizadas como sinônimas, elas guardam diferenças importantes, sendo a pluriatividade a mais adequada para a análise da dinâmica agrícola, visto que seu foco de análise é a família, e não somente o chefe. Assim, está pautada na possibilidade de combinação de atividades diferenciadas por toda a família, de acordo com a sazonalidade do trabalho agrícola, bem como na viabilidade de parte da família dedicar-se integralmente às atividades agrícolas e parte a outras atividades, ou seja, conforme lembra Schneider (1999) trata-se da combinação de mais de uma atividade ocupacional por pessoas que pertencem a uma mesma família, sendo que dependo do contexto em que as famílias estão inseridas essas atividades podem assumir grande variedade.

Ademais, a noção de pluriatividade abarca além da dimensão econômica, pois conforme exposto por Graziano da Silva (1998) inclui atividades, realizadas pelos produtores, que nem sempre são remuneradas em dinheiro, mas, com pagamento através de trocas de serviços e outros arranjos informais, ou seja, ocorrem processos que envolvem funções sociais e culturais.

Em nível de Brasil, pode-se inferir que o contexto de crise econômica da década de 1980, e a abertura comercial nos anos seguintes, colocando no mercado interno produtos subsidiados vindos de outros países, viabilizaram a diversificação de atividades no espaço rural como forma de garantir a permanência do homem no campo. Diante desse contexto, devemos considerar a pluriatividade como estratégia para reter a população rural pobre no seu local de moradia e elevar seu nível de renda conforme apontado Graziano da Silva (1998).

Ao congregar questões como contribuição à segurança alimentar; à preservação ambiental; às funções econômica e social e a manutenção do tecido 
social e cultural, surge também em contexto europeu a noção de multifuncionalidade, no sentido que além de sua função primária de produção de fibras e alimentos, a atividade agrícola tem várias outras funções relacionadas com a conservação dos solos, da biodiversidade, dos recursos naturais, etc. cujas funções são discutidas em grandes eventos por organizações e universidades.

As modificações no espaço rural brasileiro são notórias e amplamente reconhecidas e discutidas, sendo a pluriatividade um dos fenômenos de destaque. Mendes (2005) aponta que essa seria uma forma de promover a fixação do homem no campo e reduzir os efeitos negativos do processo de modernização. Porém, deve-se considerar, além desse viés predominantemente "econômico", a dimensão social e de cidadania, intrínsecos à noção de multifuncionalidade da agricultura familiar, na medida em que firma uma gama de relações com a segurança alimentar, com destaque para o provimento de alimentos; com a função ambiental, enfatizando a conservação dos solos, águas e da biodiversidade; com a função econômica apresentada a sua eficiência econômica e a com função social no âmbito desde os valores culturais, conforme ressaltado por Maluf (2003), até a geração de emprego e renda segundo Soares (2001).

Em decorrência da concretização do processo de globalização, da reestruturação econômica e espacial, e da presença de problemas sociais, econômicos e ambientais frutos das políticas adotadas nas últimas décadas de um lado; bem como do reconhecimento das potencialidades da agricultura familiar no sentido de fornecer gêneros alimentícios ao mercado interno, de gerar de emprego e renda, de garantir a qualidade de vida, de outro lado, assiste-se uma intensificação na valorização da agricultura familiar nos anos de 2000, conforme colocado por Wanderley (2000, p.24) "pela primeira vez na história, a agricultura familiar foi oficialmente reconhecida como um ator social".

Esse reconhecimento deve-se à racionalidade e potencialidade especificas dessa tipologia de agricultores. Conforme Altieri (2004, p. 22),

Os sistemas de cultivo tradicionais fornecem $20 \%$ da oferta de alimentos no mundo. [...] Os policultivos constituem no mínimo de $80 \%$ da área cultivada da África Ocidental e boa parte da produção de alimentos básicos nos trópicos latino-americanos.

Sob essa perspectiva, influenciada por condições históricas pode-se inferir a ocorrência da concentração das unidades produtivas familiares em determinadas áreas, formando "agrupamentos" de pequenas propriedades. 
Assim sendo, a partir da pressão política e do reconhecimento da capacidade político-estratégica, bem como da eficiência em absorver os progressos tecnológicos e responder a demanda do setor urbano industrial da agricultura familiar, portanto segundo uma nova forma de desenvolvimento rural, fundamentada na sustentabilidade e maior autonomia dos agricultores familiares, surgem as politicas de desenvolvimento territorial rural.

De tal modo ainda que tardiamente, de forma incipiente, com obstáculos e equívocos se comparado com a realidade de outros países, foram implantadas no Brasil algumas políticas públicas voltadas para a agricultura familiar, como o caso do Programa Nacional de Fortalecimento da Agricultura Familiar, criado a partir do Plano de Fortalecimento da Agricultura Familiar (PLANAF) lançado em 1995 e regulamentado em 28 de julho de 1996, com o Decreto Presidencial no 1.946, como programa (PRONAF), o Programa Aquisição de Alimentos (PAA) instituído em 2003, a fim de que a governo adquirisse alimentos da agricultura familiar, comunidades tradicionais para fornecer a instituições sociais, a Lei da Alimentação Escolar (2009), que determina que $30 \%$ dos recursos do FNDE para compra merenda sejam da agricultura familiar. Assim como a normativa de Agricultura Familiar, Lei n⒒ 326 de 2006, que define agricultura familiar.

Ao considerar o PRONAF, destaca-se que ao pautar-se na noção de gestão social, fundamentada na descentralização; na participação e no estabelecimento de parcerias, reconhecendo, que o desenvolvimento rural requer a sinergia entre as ações em várias escalas, o programa nas palavras de Abramovay (1998) "introduziu um primeiro enfoque territorial na política agrícola". No entanto, conforme apontado por Hespanhol (2000) e Guanziroli (2006) em virtude de pressões políticas e a extinção do Programa de Crédito Especial para a Reforma Agrária - PROCERA, o PRONAF não estaria atendendo, prioritariamente os agricultores dos estratos mais fragilizados com capacidade de ascensão, conforme recomendado, mas ao contrário os agricultores familiares do "topo da escala". Sob a mesma perspectiva, autores como Guanziroli (2006) reconhece que, no leque de agricultores familiares os mais beneficiados seriam aqueles que participaram da modernização conservadora, e complementa que, podemos verificar alta participação das liberações para fumo e soja sobre o total financiado; e paralelamente, baixíssima participação de liberações para a produção de arroz, feijão e outros produtos dirigidos ao mercado interno.

Guanziroli (2006) coloca que em muitos estabelecimentos familiares marginalizados a Renda Monetária é negativa, necessitando de recursos externos, 
como aposentadoria, para investir na propriedade, sendo assim, uma política de crédito focalizada nos setores mais carentes do meio rural poderia ser um contrassenso, já que eles não têm atividade que sustente ou demande esse tipo de política, o que justifica a necessidade de políticas agrárias e sociais e não de crédito, conforme a proposta de 1996 da (FAO/INCRA).

Já ao considerar a Lei no 11.326, promulgada em 2006 que estabelece a conceituação oficial de agricultura familiar a ser utilizada pelas políticas públicas nacionais, que dispõe, in verbis, que:
Artigo 3o: Para fins desta lei, considera-se agricultor familiar e empreendedor familiar rural aquele que pratica atividades no meio rural, atendendo, simultaneamente, aos seguintes requisitos:
I-Não detenha a qualquer título, área maior que 4 módulos fiscais;
II-Utilize predominantemente mão-de-obra da própria família nas atividades econômicas do seu estabelecimento ou empreendimento;
III-Tenha percentual mínimo de renda familiar originada de atividades econômicas do seu estabelecimento ou empreendimento, na forma definida pelo Poder Executivo; (Lei 12.512, de 2011);
IV-Dirija seu estabelecimento ou empreendimento com sua família.

Cabe ressaltar que esta representou o reconhecimento pelo Estado Brasileiro do valor econômico e social da agricultura familiar para o país e da obrigação do Poder Público, sendo o seu fomento uma obrigatoriedade do Estado de não de governos. Contudo, a norma tem sido alvo de críticas, principalmente pelo fato de não evidenciar/beneficiar a diversidade e especificidades dos agricultores inseridos na prática da agricultura familiar, mas que não preenchem os requisitos objetivos. Deste modo, vários estudiosos como Carneiro (2008) defendem a necessidade de ampliar o conjunto de parâmetros que definem quem é e quem não é agricultor familiar em cada espaço rural, atém mesmo com a inclusão de elementos subjetivos, como considerando valores, práticas e percepções.

\section{Abordagem do agronegócio e da agricultura familiar no ensino fundamental}

Com o intuito de compreender a forma como são abordados no ensino fundamental II, os temas relacionados ao espaço rural brasileiro, nomeadamente os conteúdos inerentes aos dilemas que permeiam a questão do agronegócio e da agricultura familiar na atualidade, observou-se como a temática está colocada nos livros didáticos de Geografia. Neste sentido, ressalta-se tais conteúdos, geralmente são abordados no sétimo ano, sendo que o foco não é a qualidade dos livros 
didáticos, mas sim problematizar como a temática é abordada, buscando identificar o posicionamento o discurso dos autores acerca da temática.

\section{Análise do Livro "A"}

A primeira obra analisada, aqui denominada de livro "A", aborda espaço rural brasileiro, em um capítulo, sendo a discussão acerca das questões do agronegócio e da agricultura familiar na atualidade bem sucinta, sem uma preocupação em distinguir agronegócio e agricultura familiar.

Ao tratar da urbanização brasileira, os autores citam os problemas do campo, como as péssimas condições de trabalho dos trabalhadores assalariados, os chamados boias-frias, inclusive com a fotografia de um cortador de cana-de-açúcar.

No capítulo reservado ao espaço rural, denominado "O espaço agrário e a questão da terra", de modo geral, é destacada a importância da agropecuária no Brasil. Sendo que sobre as grandes culturas comerciais são apresentados os custos ambientais e sociais, inclusive é ressaltado que "em 2013, segundo o Ministério do Trabalho e Emprego do Brasil, foram libertadas do trabalho escravo 2063 pessoas em vários ramos de atividades, incluindo a agricultura e a pecuária" (ADAS e ADAS, 2017).

Apesar de ser tratada de modo bem sintético, a presença de mapas do Brasil com a distribuição espacial das lavouras comerciais e rebanho bovino, permitem a observação das diferenças regionais.

No entanto, não se aborda sobre os sujeitos históricos importantes na constituição do espaço agrário brasileiro como os camponeses, os índios, os negros e os atuais agricultores familiares, os quais são citados de forma superficial, quando os autores apresentam a noção de culturas especializadas, que se contrapõem as culturas comerciais.

Ao abordar as desigualdades no campo, os autores destacam a questão agrária, apresentando a classificação dos estabelecimentos rurais, por número e área, a fim de enfatizar a concentração fundiária, e em seguida referir-se ao Movimento dos Trabalhadores Rurais Sem Terra (MST) destacando o contexto de surgimento e os luta por acesso a terra e os desafios enfrentados contra as injustiças socioeconômicas, de certo modo, apontam para a urgência da reforma agrária. 


\section{Análise do Livro "B"}

No livro "B" os autores abordam o espaço rural em três capítulos, o primeiro, que faz um resgate histórico e caracteriza de modo geral a organização do espaço rural brasileiro na atualidade, é intitulado "Características da Agricultura no Brasil"; o segundo trata da questão da modernização do espaço rural considerando tanto as pequenas como as grandes propriedades, assim versa sobre a difusão do agronegócio e as transformações na produção nas pequenas propriedades a partir do processo de integração da produção, este capitulo tem como título "Modernização do Campo"; por fim, o terceiro capítulo, cujo título é "Problemas do Mundo Rural" aborda a questão agrária, como foco na distribuição de terra e nos problemas socioeconômicos enfrentados pelos trabalhadores rurais.

Deste modo, observa-se que no $B$, além de aprofundar nas discussões conceituais e conjunturais das formas de organização e produção no campo brasileiro, os autores assumem uma orientação teórico-metodológica baseada no marxismo-histórico dialético. Eles reconhecem a diversidade, a complexidade e as desigualdades inerentes ao espaço rural brasileiro, cuja realidade decorre do processo de reprodução do capital durante a formação socioespacial brasileira, que propiciou a concentração fundiária.

Considerando os conceitos de agronegócio e de agricultura familiar, é apresentando o conceito de agronegócio, enquanto "cadeia produtiva que envolve a produção agropecuária, a transformação dos gêneros agropecuários em produtos industrializados e a distribuição e venda destes produtos", além "da produção e comercialização de insumos agrícolas, maquinas e equipamentos destinados ao setor" (SAMPAIO e MEDEIROS, 2017), portanto segundo uma visão que convergem com a perspectiva da academia, conforme exposto previamente neste texto. Ainda sobre o agronegócio no livro B é destacada a relevância de produtos voltados para a exportação como o café, a laranja e soja, sendo que os problemas como a precariedade das condições de trabalho e a luta pela terra são abordados de forma competente no terceiro capítulo. Cabe destacar que este capítulo aborda o conceito de reforma agrária, seu histórico e relevância para mitigar problemas sociais historicamente presentes no Brasil, como a concentração fundiária, conceito também exposto neste livro didático.

Já com relação à noção de agricultura familiar os autores destacam a amplitude do termo que, "engloba tanto a agricultura de subsistência quanto as 
pequenas propriedades modernas, desde que se fundamentem no trabalho familiar" (SAMPAIO e MEDEIROS, 2017), também ressaltam o seu papel na produção de alimentos, na geração de empregos no campo, assim como para a preservação ambiental. Neste caso, os autores apresentam em um box, o conceito de sistema de agroflorestal. Ainda no âmbito do tratamento dado a agricultura familiar os autores do livro B, citam o PRONAF para ressaltar a importância de que os agricultores tenham acesso ao crédito para viabilizar a produção.

Por fim, é destacado neste livro que as áreas onde predominam o agronegócio são aquelas com maior concentração de latifúndios, enquanto que nas áreas de predomínio de agricultura familiar é significativo o número de pequenas propriedades, os minifúndios.

\section{Considerações Finais}

No contexto atual, com a reestruturação do capitalismo, a globalização, o neoliberalismo, mas também com o reconhecimento das potencialidades da agricultura familiar tornam-se mais evidente os dilemas entre a agricultura familiar e o agronegócio, bem como internamente, considerando as contradições que existem em cada um destas duas formas de produção.

Certamente, os atuais impasses têm raízes no processo de modernização agropecuária, quando ocorreu a priorização do modelo agrícola produtivista baseado no agronegócio, para dar respostar imediatas aos interesses do capital e que engendrou intensas desigualdades na área rural, ao acelerar o êxodo rural e intensificar a tecnificação da agricultura, sem levar a uma distribuição igualitária de oportunidades. Conforme afirmou Oliveira (1987) o desenvolvimento do capitalismo no território brasileiro é contraditório e combinado (e faz de forma heterogênea, complexa e, portanto, plural) Isso quer dizer que, ao mesmo tempo em que esse desenvolvimento avança reproduzindo relações especificamente capitalistas [...], ele (o capitalismo) produz também, igual e contraditoriamente, relações camponesas de produção [...].

Considerando a agricultura familiar, dentre os impasses, pode-se destacar, por exemplo, a questão desta forma de produção estar fadada ao desaparecimento, e/ou o reconhecimento de sua capacidade de renovação a partir da capacidade de sua capacidade de absorver os progressos tecnológicos e, deste modo reforçar sua importância, renovando assim a concepção de agricultura familiar, diferentemente de outrora, quando esta era entendida como contrária ao capitalismo. 
Nesta perspectiva é necessária a implementação de políticas agrícolas direcionadas à agricultura familiar, não como mero assistencialismo, mas no sentido de contribuir na melhoria do nível tecnológico, na viabilização dos agricultores a terra, na prática do associativismo, a assistência técnica, o crédito rural e a apropriação da cadeia agroalimentar por parte do agricultor familiar, no sentido de que estes também consigam dominar a produção, "antes, dentro e depois da porteira". É como se fosse possível uma outra globalização não perversa, conforme afirma Milton Santos, mas um movimento de apropriação dos recursos técnicos e científicos, em prol do fortalecimento de uma agricultura familiar.

A análise feita em nos livros didáticos, reconhecendo as limitações inerentes a tais materiais, permite afirmar que a abordagem da questão do agronegócio e da agricultura familiar apresenta-se sob vários enfoques e concepções teóricometodológicas, sendo que, por vezes tais temas não são abordados, e/ou são tratados de forma superficial, em contraposição à priorização de outras temáticas inerentes ao espaço rural brasileiro. Comparativamente, o livro B se sobressai, nele o conteúdo é apresentado considerando a formação socioespacial do Brasil, bem como a complexidade inerente ao território do país, considerando nomeadamente a coexistência de diferentes lógicas e formas de produção no espaço rural. Também são considerados os problemas históricos inerentes à questão agrária brasileira. Conteúdo, apesar desta obra reconhecer o papel da agricultura familiar, o tema não é abordado com profundidade.

Neste sentido, cabe destacar o papel que os professores têm em complementarem o material a ser trabalhado e contemplar com questões relevantes no que concerne à tais temáticas.

Além disso, de modo compreender o rural brasileiro na contemporaneidade, nomeadamente os impasses entre o agronegócio e a agricultura familiar, enfatiza-se a importância de tratar a unidade e a totalidade das esferas econômica, social, politica e cultural da sociedade em determinado período, ou seja, de contextualizar temporal e espacial a formação socioespacial do país, para compreender que esta realidade foi e está sendo construída e modificada incessantemente, portanto apresenta-se como possibilidade em aberto.

Recentemente vários pesquisadores têm se dedicado a compreender o rural a partir de categorias simbólicas produzidas pelos agentes sociais, o que implica, em sala de aula, na valorização da cultura, da diversidade, dos modos de vida, da 
produção e da importância que o campo ocupa na sociedade em geral e na vida de seus habitantes em específico.

\section{REFERÊNCIAS}

ABAGRP, Associação Brasileira do Agronegócio da Região de Ribeirão Preto, 2019. Disponível em: < http://www.abagrp.org.br/agronegocioConceito.php>. Acesso em: 05 de jan. 2019.

ALENTEJANO, P. R. R. Reforma agrária e pluriatividade no Rio de Janeiro: repensando a dicotomia rural-urbana nos assentamentos rurais. 1998. 201f. Dissertação (Mestrado em Geografia)- CPDA/UFRRJ, Rio de Janeiro, 1998.

ADAS, M.; ADAS, S. Expedições Geográficas. São Paulo: Moderna, 2017.

ALTIERI, M. Agroecologia - A dinâmica produtiva da agricultura sustentável. Porto Alegre: Editora da UFRGS, 2004.

ANJOS, F. S. dos. Agricultura familiar em transformação: os colonos-operários de Massanraduba (SC). Pelotas: UFPEL, 1995. 120p.

BRASIL. Lei n. 11.326, de 24 de julho de 2006. Diário Oficial da União de 25.7.2006. Disponível em: http://www.planalto.gov.br/ccivil_03/_ato2004-2006/2006/lei/l11326.htm. Acesso em:10 jan. 2019.

BRUNO, R. Desigualdade, agronegócio, agricultura familiar no Brasil. Estudos Sociedade e Agricultura, v. 24, n.1. 2016, p. 142- 160.

CANUTO, A. Agronegócio: a modernização conservadora que gera exclusão pela produtividade. Revista Nera - Ano 7, n. 5 - Agosto/Dezembro De 2004.

CARNEIRO, M. J. Em que consiste o familiar da agricultura familiar? In: COSTA, L. F. C.; FLEXOR G.; SANTOS, R. (orgs.). Mundo rural brasileiro: ensaios interdisciplinares. Rio de Janeiro: Mauad X; EDUR. 2008.

CASTILLO, R. Agronegócio e logística em áreas de Cerrado: expressão da agricultura científica globalizada. Revista da ANPEGE. v. 3, 2007, p. 21-27.

DAVIS, J. H.; GOLDBERG, R. A. A concept of agribusiness. Division of Research. Graduae School of Business Administration. Boston: Harvard University, 1957.

DELGADO, G. C. Especialização primária como limite ao desenvolvimento. Desenvolvimento em debate, v.1, n.2, p.111-125, janeiro-abril e maio-agosto 2010. Disponível em: <http://desenvolvimentoemdebate.ie.ufrj.br/pdf/dd_guilherme.pdf>. Acesso em: 05 jan. 2019.

A Questão Agrária no Brasil, 1950-2003. Instituto de Pesquisa Econômica Aplicada (Ipea), 2008.

DELGADO, N. G. O papel do rural no desenvolvimento nacional: da modernização conservadora dos anos 1970 ao Governo Lula. Brasília: CONDRAF/MDA, 2010. p.28-78. Disponível em: 
http://www.mda.gov.br/sitemda/sites/sitemda/files/user_arquivos_19/Livro\%20Brasil\%20Rur al\%20em\%20Debate.pdf >. Acesso em: 05 jan. 2019.

ELIAS, D. Globalização e agricultura. São Paulo: EDUSP, 2003.

FARIA, N. M. X. Modelo de desenvolvimento, agrotóxicos e saúde: prioridades para uma agenda de pesquisa e ação. Rev. bras. Saúde ocup., São Paulo, v.37, n.125, p. 17-50, 2012.

FERNANDES, B. M. Um nome para "modernizar" o sistema de latifúndio. 2006. Disponível em: <http://www.unesp.br/aci/jornal/211/supled.php>. Acesso em: 05 jan. 2019.

Questão Agrária, Pesquisa e MST. São Paulo, Cortez Editora, 2001.

GONÇALVES, C. W. P. Geo-Grafias: movimentos socialies, nuevas territorialidades y sustentabilidad. México: Siglo Veintiuno, 2001.

Prefácio. In: A colonialidade do saber: eurocentrismo e ciências sociais. Perspectivas latino- americanas. LANDER, E. (org). Coleccion Sur Sur, CLACSO, Ciudad Autônoma de Buenos Aires, Argentina. setembro 2005.

GRAZIANO DA SILVA, J. A nova dinâmica da agricultura brasileira. Campinas: Unicamp, 1998.

Questão Agrária e Sindicalismo Rural -Entrevista. História e Perspectivas. Uberlândia, v.50, p. 161-196, jan./jun. 2014.

GUANZIOLI, C. E. et al. Agricultura familiar e reforma agrária no século XXI. Rio de Janeiro: Garamond, 2001. 288 p.

HESPANHOL, R. A. M. Produção familiar: perspectiva de análise e inserção na microrregião geográfica de Presidente Prudente. $354 \mathrm{f}$. Tese (Doutorado em Geografia) Instituto de Geociências e Ciências Exatas, Universidade Estadual Paulista, Rio Claro, 2000.

MALUF, R. S. A multifuncionalidade da agricultura na realidade rural brasileira. In: CARNEIRO, Maria Jose; MALUF, R. S. (Org.). Para além da produção: Multifuncionalidade e Agricultura Familiar. Rio de Janeiro: MAUAD. 2003. p. 135-152.

MATOS, P. F; PESSÔA, V. L. S. O agronegócio no cerrado do sudeste goiano: uma leitura sobre Campo Alegre de Goiás, Catalão e Ipameri. Soc. \& Nat., Uberlândia, ano 24 n. 1, 3750, jan/abr. 2012.

MENDES, E. de P. P. A produção rural familiar em Goiás: as comunidades rurais no município de Catalão (GO). 294 f. Tese (Doutorado em Geografia) - Faculdade de Ciência e Tecnologia, Universidade Estadual Paulista, Presidente Prudente, 2005.

NAVARRO, Z. PEDROSO, M. T. M. Agricultura familiar: é preciso mudar para avançar. Brasília, DF : Embrapa Informação Tecnológica, 2011. 248 p.

OLIVEIRA, A. U. de. Modo capitalista de produção e agricultura. São Paulo: Ática, 1987.

OLIVEIRA, A. U. de. Agricultura Camponesa no Brasil. 3 ed. São Paulo: Contexto, 1997.

A Amazônia e a nova geografia da produção da soja. Terra livre, São Paulo, ano 22, v. 1, n. 26, p. 13-43, jan.-jun., 2006. 
PAULINO, E. T. Camponeses e indústrias: aspectos da integração no norte do Paraná. In: III Simpósio Nacional de Geografia Agrária, II Simpósio Internacional de Geografia Agrária...Anais... Presidente Prudente: UNESP, 2005.

PAULINO, E. T. Por Uma Geografia Dos Camponeses - 2ª Ed,Unesp. 2006.

SAMPAIO, C. P. da S. Agricultura Familiar: Bloqueios e precariedades. In: CONCRESSO BRASILEIRO DE ECONOMIA E SOCIOLOGIA RURAL, XL, 2002. Passo Fundo. Anais... Passo Fundo: SOBER/UPF, 2002. CD-ROM.

SAMPAIO, F. dos S.; MEDEIROS, M. C. Para Viver Juntos. São Paulo: Edições SM, 2017.

SANTOS, M. A natureza do espaço: técnica e tempo, razão e emoção. 4.ed. São Paulo: HUCITEC, 2006.

SCHNEIDER, S. Agricultura familiar e pluriatividade. In: Agricultura familiar e industrialização: pluriatividade e descentralização industrial no Rio Grande do Sul. Porto Alegre: UFRGS, 1999. p. 165-194. Série Estudos Rurais.

A Diversidade da Agricultura Familiar. Porto Alegre: Ed. UFRGS, 2009.

SOARES, A. C. A multifuncionalidade da agricultura familiar. Proposta, São Paulo. n. 87, p.40-49, dez./fev. de 2000/2001.

WANDERLEY, M. N. B. Raízes históricas do campesinato brasileiro. In: TEDESCO, J. C. (Org.). Agricultura familiar: realidades e perspectivas. 3. ed. Passo Fundo: UPF, 2000. p. 21- 56 .

WILKINSON, J. A pequena produção e sua relação com os sistemas de distribuição. Ponencia realizada para El Seminario de Políticas de Seguridad Alimentaria y Nutricion en America Latina. FODEPAL. Campinas, Brasil, Outubro e 2003.

\section{NOTAS DE AUTOR}

\section{CONTRIBUIÇÃO DE AUTORIA}

Lidiane Aparecida Alves - Concepção. Coleta de dados, Análise de dados, Elaboração do manuscrito, revisão e aprovação da versão final do trabalho

\section{FINANCIAMENTO}

Não se aplica.

\section{CONSENTIMENTO DE USO DE IMAGEM}

Não se aplica.

\section{APROVAÇÃO DE COMITÊ DE ÉTICA EM PESQUISA}

Não se aplica.

CONFLITO DE INTERESSES

Não se aplica.

\section{LICENÇA DE USO}

Este artigo está licenciado sob a Licença Creative Commons CC-BY. Com essa licença você pode compartilhar, adaptar, criar para qualquer fim, desde que atribua a autoria da obra.

\section{HISTÓRICO}

Recebido em: 01-02-2019

Aprovado em: 18-03-2019 